Elsevier required licence: ( 2019

This manuscript version is made available under the CC-BY-NC-ND 4.0 license http://creativecommons.org/licenses/by-nc-nd/4.0/

The definitive publisher version is available online at

10.1016/j.ica.2018.12.014 


\title{
Conversion Of Single Crystals of a Nickel(II) Dithiocarbamate Complex to Nickel Sulfide Crystals
} Alexander Angeloski, ${ }^{\mathrm{a}}$ Michael B. Cortie, ${ }^{\mathrm{a}} \mathrm{John}$. A. Scott, ${ }^{\mathrm{a}}$ Dayanne M. Bordin, ${ }^{\mathrm{a}}$ and Andrew M.
McDonagh ${ }^{\mathrm{a}^{*}}$

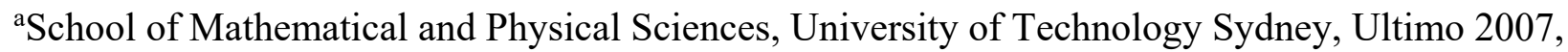
Australia

Corresponding author email address: Andrew.McDonagh@uts.edu.au

\begin{abstract}
Single crystals of bis $\left(\kappa^{2} \mathrm{~S}, \mathrm{~S}^{\prime}\right.$-di(isopropyl)dithiocarbamato) nickel(II) were utilized as a single source precursor for the formation of NiS via thermolysis. The complex decomposed at $\sim 250$ ${ }^{\circ} \mathrm{C}$ to form $\alpha$-NiS exclusively with no $\beta$-NiS detected. Analysis of the thermolysis regime using in situ techniques showed that the thermolysis occurs in a single step with the major volatile sideproducts being isopropyl-isothiocyanate and carbon disulfide. The resultant NiS was examined using SEM and TEM to reveal a retention of precursor crystal edge-length and angle relationships.
\end{abstract}

Keywords: Dithiocarbamate $・$ Nickel $\bullet$ Thermolysis 


\section{Introduction}

Nickel sulfides are renowned for their superb chemical and physical properties, which have stimulated a great deal of attention in areas such as, but not limited to, catalytic water splitting, ${ }^{[1-8]}$ heterogeneous catalysis, ${ }^{[9]}$ supercapacitors, ${ }^{[10-13]}$ batteries $^{[14-20]}$ and solar cells. ${ }^{[21-27]}$ These cuttingedge applications have aroused an impressive level of attention towards manipulation of the morphology of nickel sulfide materials. ${ }^{[8,28-33]}$ Unfortunately, these efforts are complicated by the propensity of nickel sulfides to exist in a range of phases, and stochiometries, such as $\mathrm{NiS}, \mathrm{NiS}_{2}$, $\mathrm{Ni}_{3} \mathrm{~S}_{2}, \mathrm{Ni}_{3} \mathrm{~S}_{4}, \mathrm{Ni}_{6} \mathrm{~S}_{5}, \mathrm{Ni}_{7} \mathrm{~S}_{6}, \mathrm{Ni}_{9} \mathrm{~S}_{8} .{ }^{[34-39]}$ From a synthetic standpoint, these issues provide challenges when attempting to isolate individual, targeted compounds, ${ }^{[34,40]}$ which is of fundamental importance as each phase possesses somewhat distinct properties.

Techniques utilizing separate reactants have been applied to the synthesis of $\mathrm{Ni}_{\mathrm{x}} \mathrm{S}_{\mathrm{y}}$ compounds, with varying degrees of success. Synthetic methods include solvo- and hydrothermal, ${ }^{[20,41-46]}$ solidstate, ${ }^{[47-49]}$ microwave-assisted, ${ }^{[11,17]}$ spray pyrolysis ${ }^{[50,51]}$ and solution-based ${ }^{[52]}$ techniques. In these cases, the phase and morphology of the resultant $\mathrm{Ni}_{\mathrm{x}} \mathrm{S}_{\mathrm{y}}$ material is adjusted by varying the solvent, capping ligand, precursors, reaction temperature and time.

An alternative approach employs single-source precursors (SSPs) that provide control of reactant stoichiometry and the potential to tune their thermal properties through ligand design. An ability to adjust both the stoichiometry and thermal properties by manipulation of the SSP structure can at times allow for control of the phase and morphology of the resultant materials.

There has been considerable interest in the development of SSPs for the synthesis of nickel sulfides, with a focus on SSPs with $\mathrm{NiS}_{4}$ geometry such as dithiocarbamates ${ }^{[34,53-61]}$ and xanthates. ${ }^{[35,48,62-65]}$ Furthermore, insight into the processes involved during the thermal conversion of SSPs is important to allow for manipulation of the SSP structure to achieve suitable properties such as low reaction temperature and/or selective nanostructures as shown in recent studies utilizing low-temperature melts of xanthates. ${ }^{[66]}$ The role of amines in the solution-state thermolysis of nickel dithiocarbamates 
has been investigated ${ }^{[54,56,59]}$ although no studies focusing on the processes involved in the solid state decomposition of nickel dithiocarbamates into nickel sulfide nanostructures are extant.

Nickel(II) sulfide (NiS), of relevance to this work, has two polymorphic phases, with a thermodynamically stable low temperature rhombohedral phase $\left(\beta, \mathrm{R}_{3} m\right)$ and a metastable high temperature hexagonal phase $\left(\alpha, \mathrm{P} 6_{3} / \mathrm{mmc}\right)$. In the $\beta$ form, $\mathrm{Ni}^{\mathrm{II}}$ atoms are surrounded by five sulfur atoms forming a tetragonal bipyramidal geometry, whilst in the $\alpha$ form $\mathrm{Ni}^{\mathrm{II}}$ atoms are octahedrally coordinated to six sulfur atoms. The transformation between $\alpha$ to $\beta$ occurs between 280 to $380{ }^{\circ} \mathrm{C}$ with a volume change of $\sim 4 \%{ }^{[35,36,67,68]}$

Whilst examining an unusual $\mathrm{C}-\mathrm{H} \cdots \mathrm{Ni}$ anagostic interaction within crystals of the title compound, ${ }^{[61]}$ we also observed that the complex decomposed to produce NiS at elevated temperatures. Here we investigate the transformation of the nickel bis-diisopropyldithiocarbamate $\mathrm{SSP}$, bis $\left(\kappa^{2} \mathrm{~S}, \mathrm{~S}^{\prime}-\right.$ di(isopropyl)dithiocarbamato) nickel(II), Ni(DIPDTC)2, (Figure 1) which yields a novel nickel sulfide (NiS) nanostructure, and show that the high temperature $\alpha$ phase can be prepared at relatively low temperatures using this method.

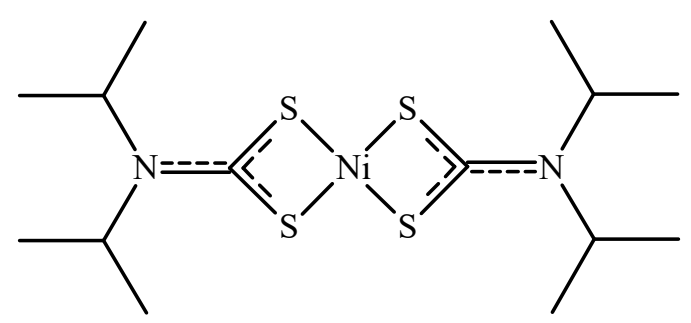

Figure 1. Chemical structure of bis $\left(\kappa^{2} \mathrm{~S}, \mathrm{~S}^{\prime}\right.$-di(isopropyl)dithiocarbamato) nickel(II).

\section{Results and Discussion}

Single crystals of $\mathrm{Ni}(\mathrm{DIPDTC})_{2}$ in the size range $200-400 \mu \mathrm{m}$ were obtained by slow evaporation of a chloroform solution. Decomposition upon heating was monitored using variable temperature isotropic light microscopy (Video S1). Photomicrographs were acquired in the temperature range 30 to $500{ }^{\circ} \mathrm{C}$ whilst heating at $3{ }^{\circ} \mathrm{C} \mathrm{min}-1$ under a flow of $25 \mathrm{~mL} \mathrm{~min}{ }^{-1}$ of nitrogen. The images reveal a transition from $\mathrm{Ni}$ (DIPDTC)2 to a solid material (Figure 2), which we show to be $\alpha$-NiS (see below). 
Cracks in the crystal surface appear at $210{ }^{\circ} \mathrm{C}$ and the crystals begin to decompose at $219{ }^{\circ} \mathrm{C}$, evidenced by the formation of gas bubbles within the crystals. Upon completion of the decomposition process, the crystal edge lengths have contracted significantly.

(a)

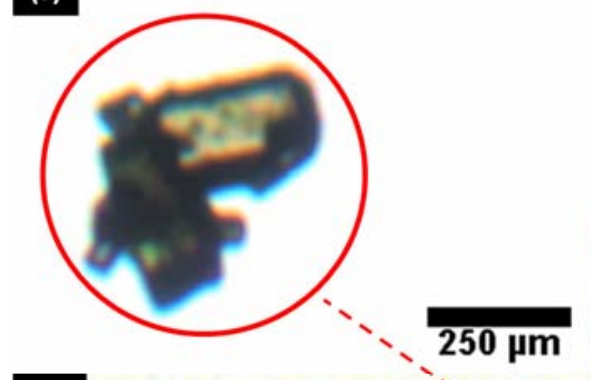

(d) (b)

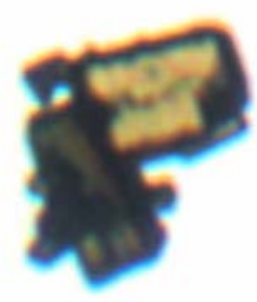

(c)

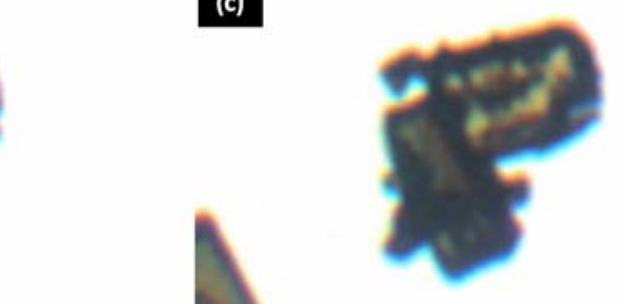

$250 \mu \mathrm{m}$

(f)

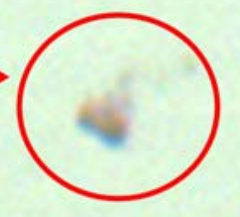

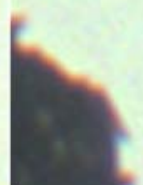

$250 \mu \mathrm{m}$

Figure 2: Variable-temperature optical image sequence extracts from Video S1 showing the decomposition of $\mathrm{Ni}(\mathrm{DIPDTC})_{2}$ at $30,189,219,243,246$ and $255{ }^{\circ} \mathrm{C}$ (a-f). Conversion of the precursor crystals to NiS is indicated in red.

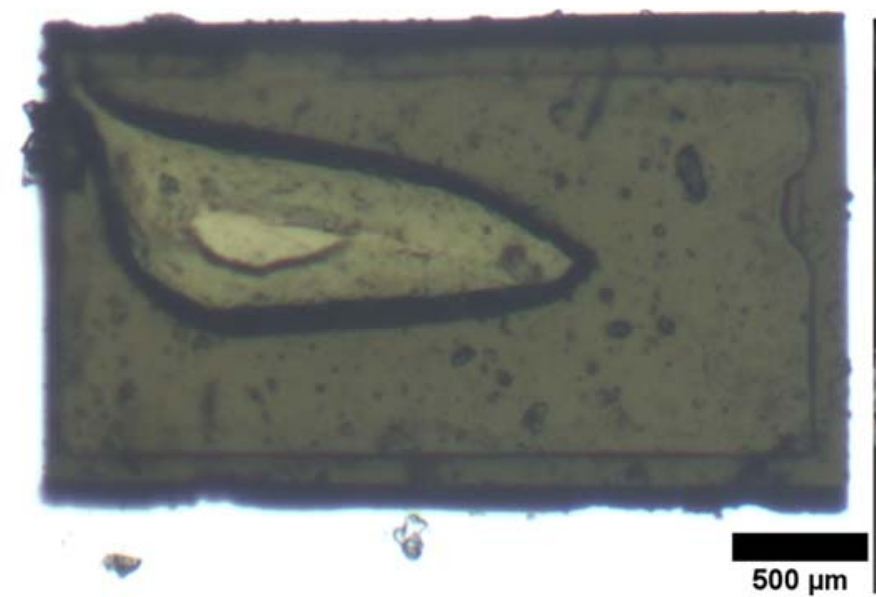

(a)

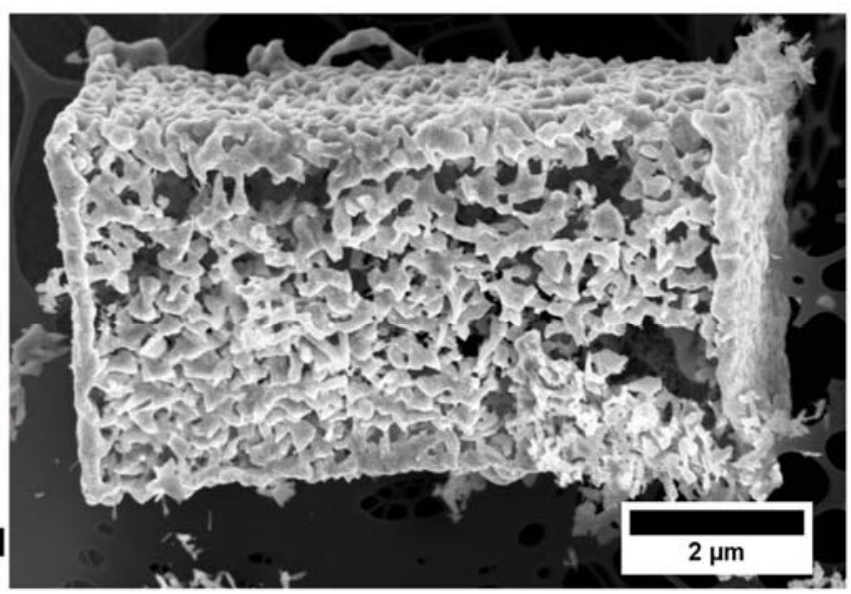

(b) 
Figure 3: (a) Optical micrograph of a typical single crystal of Ni(DIPDTC)2 before thermolysis, and (b) SEM micrograph of a block of material generated by thermolysis of a single crystal of $\mathrm{Ni}(\mathrm{DIPDTC})_{2}$.

SEM images of NiS obtained from the variable temperature optical microscopy experiment show that the residue maintained the overall cuboidal morphology of $\mathrm{Ni}(\mathrm{DIPDTC})_{2}$ crystals (Figure 3 ). That is, the ratios of the edge lengths are in agreement with those of the crystals measured using optical microscopy prior to decomposition (Figure 3). Higher magnification images of the pseudo-facet edges (Figure $4 \mathrm{~b}-\mathrm{e}$ ) reveal highly porous and textured NiS, with somewhat acicular crystallites extending from the surface. The individual crystallites do not show a preferred orientation with respect to the pseudo-facets and are present as randomly orientated aciculae. This complex 3D structure was not observed in previous thermolyses of $\mathrm{Ni}(\mathrm{DIPDTC})_{2}$ that utilized faster heating rates $\left(10{ }^{\circ} \mathrm{C} \mathrm{min}^{-1}\right)$ although the aciculae were present in the current and previous work. ${ }^{[61]}$ SEM-EDX mapping revealed that the structure contained an even distribution of $\mathrm{Ni}$ and $\mathrm{S}$ within the sample (Figure 4e).

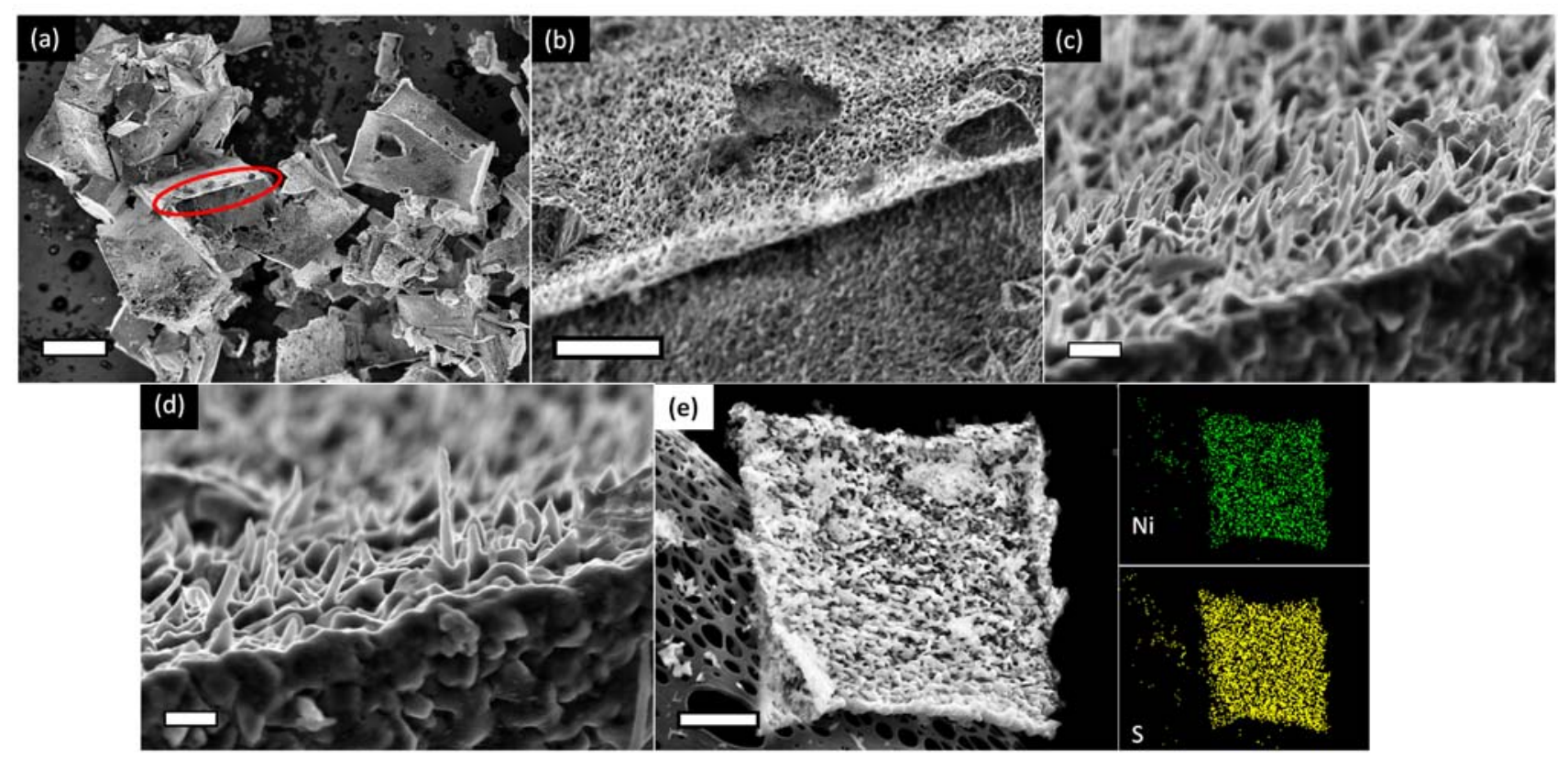

Figure 4: SE-SEM micrographs of Ni(DIPDTC)2 thermolysis residue (a-d) with EDX mapping (e) (scale bars: $40,5,0.5,0.4,0.2 \mu \mathrm{m}$ respectively). 
TEM micrographs of the resultant structure reveal a mixture of filamentous and globular NiS crystallites. SAED of the assembled structure produced a polycrystalline diffraction pattern indicating an overlap of many orientated NiS crystallites, with no preferred orientation relative to the edges of the three dimensional structures (Figure 5a). Many of the observed filamentous crystallites are attached directly to the globular structures (Figure 5b).

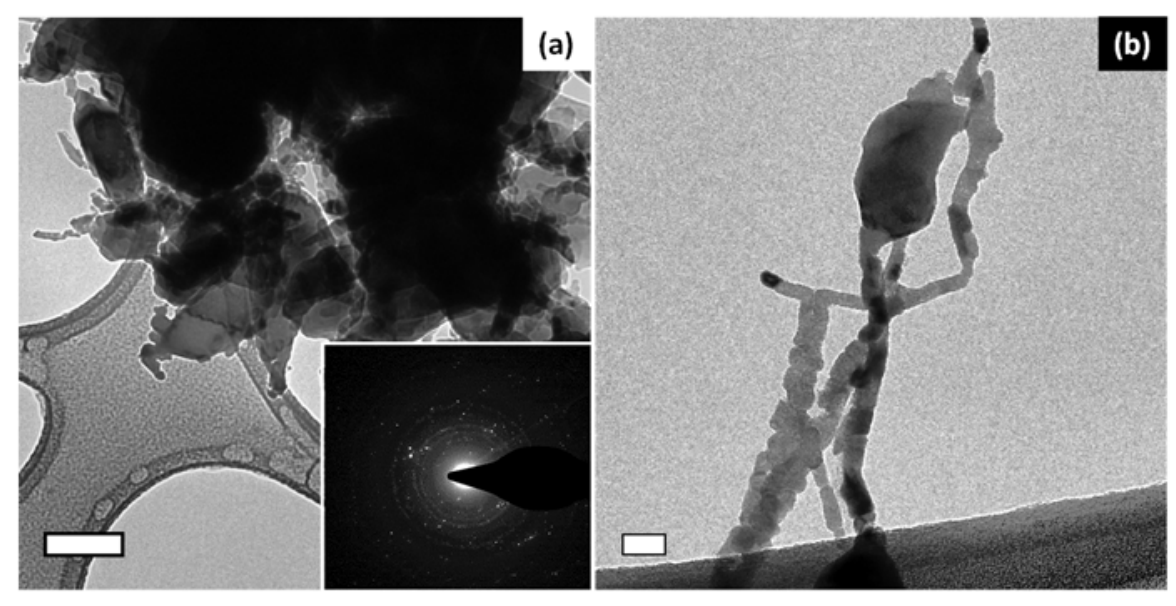

Figure 5: (a) TEM micrograph of NiS with SAED inset, scale bar: $100 \mathrm{~nm}$. (b) A NiS filament, scale bar: $20 \mathrm{~nm}$.

In situ real time synchrotron powder XRD experiments were performed to investigate the transformation of the SSP. Diffraction patterns were collected whilst Ni(DIPDTC) 2 was heated under an atmosphere of helium at a rate of $3{ }^{\circ} \mathrm{C} \mathrm{min}^{-1}$ (Figure 6). The onset of decomposition is marked by a sudden decrease in the peak area of $\mathrm{Ni}\left(\right.$ DIPDTC) 2 at $303^{\circ} \mathrm{C}$ (Figure 6) with an associated increase in the peak area for NiS. The subsequent $35^{\circ} \mathrm{C}$ is characterized by the simultaneous decomposition of $\mathrm{Ni}(\mathrm{DIPDTC})_{2}$ and the formation of $\mathrm{NiS}$, as indicated by the overlapping diffraction patterns. 

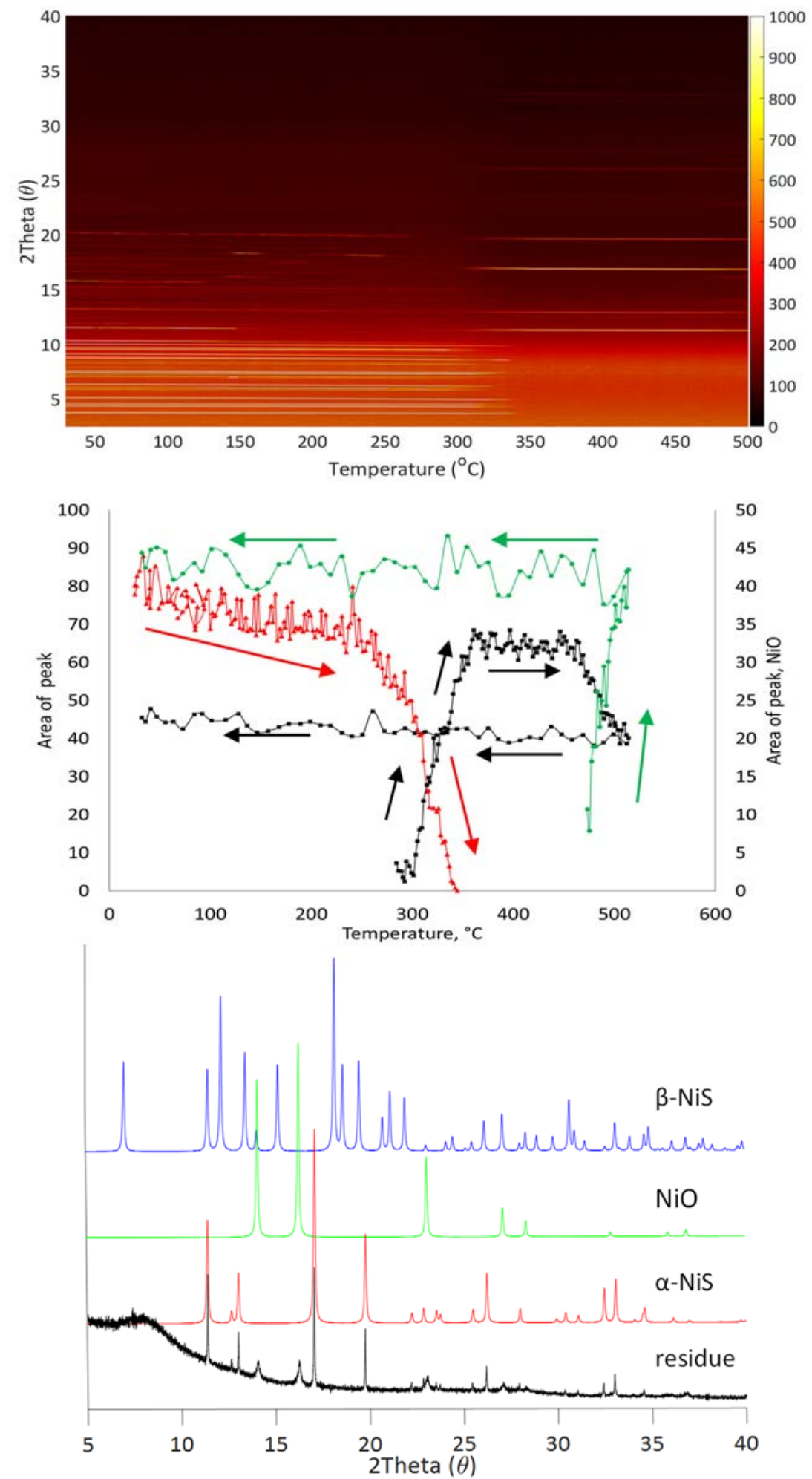

Figure 6: Powder-diffraction heatmap showing changes in diffraction peak location and intensity at temperatures between 40 to $500{ }^{\circ} \mathrm{C}$ (upper) with peak area analysis for selected X-ray diffraction peaks (middle): $\mathrm{Ni}(\mathrm{DIPDTC})_{2}\left(3.7^{\circ}\right.$, red trace $), \mathrm{NiS}\left(11.3^{\circ}\right.$, black trace $)$ and $\mathrm{NiO}\left(13.9^{\circ} \& 16.1^{\circ}\right.$, green trace). The residue after heating, with simulated patterns of expected phases is shown in the lower panel. 
All of the Ni(DIPDTC) 2 decomposed by $340{ }^{\circ} \mathrm{C}$ yielding NiS in the high temperature $\alpha$-phase (indexed using COD 9009240, Figure S1). There was no change in the peak areas assigned to NiS until $460{ }^{\circ} \mathrm{C}$, whereupon the areas decreased and peaks assigned to $\mathrm{NiO}$ (COD 4320499) appeared (Figure 6) due to partial oxidation of NiS (attributed to minute concentrations of oxygen in the protective helium flow). Oxidation halted as heating was discontinued and upon cooling to room temperature, the NiS retained the high-temperature $\alpha$-phase. ${ }^{[69]}$ The expected low temperature $\beta$-NiS phase (COD 1538656) was not detected at any stage during the experiments (Figure 6). Previous studies of the Ni-S binary phase system ${ }^{[70]}$ showed both the $\alpha$ and $\beta$ polymorphs of NiS are stable in the temperature range $282{ }^{\circ} \mathrm{C}$ to $379{ }^{\circ} \mathrm{C}$, with their relative proportions dependent on the sulfur content of the binary system. Specifically, $\beta$-NiS has Ni:S ratios in the range of $64: 36-67: 33 \mathrm{wt} \%$ and $\alpha$-NiS has Ni:S ratios in the range of $63: 37-64: 34 \mathrm{wt} \%$. Above $\sim 380{ }^{\circ} \mathrm{C}$ only the $\alpha$-phase is stable. In the current work, where $\alpha$-NiS formed between $\sim 310$ and $350{ }^{\circ} \mathrm{C}$, the SSP contains Ni and $\mathrm{S}$ in the ratio 1:4, which may favour formation of the $\alpha$-phase over the $\beta$-phase. Inductively coupled plasma-mass spectrometry analysis of the NiS prepared in this work revealed a Ni content of $63 \mathrm{wt} \%$, consistent with the $\alpha$-phase stoichiometry. Furthermore, no $\mathrm{Ni}_{3} \mathrm{~S}_{4}$ or $\mathrm{NiS}_{2}$ were detected in the X-ray diffraction patterns of the decomposition product, which we attribute to the considerable proportion of the S content of the precursor that was volatilized (see below). 

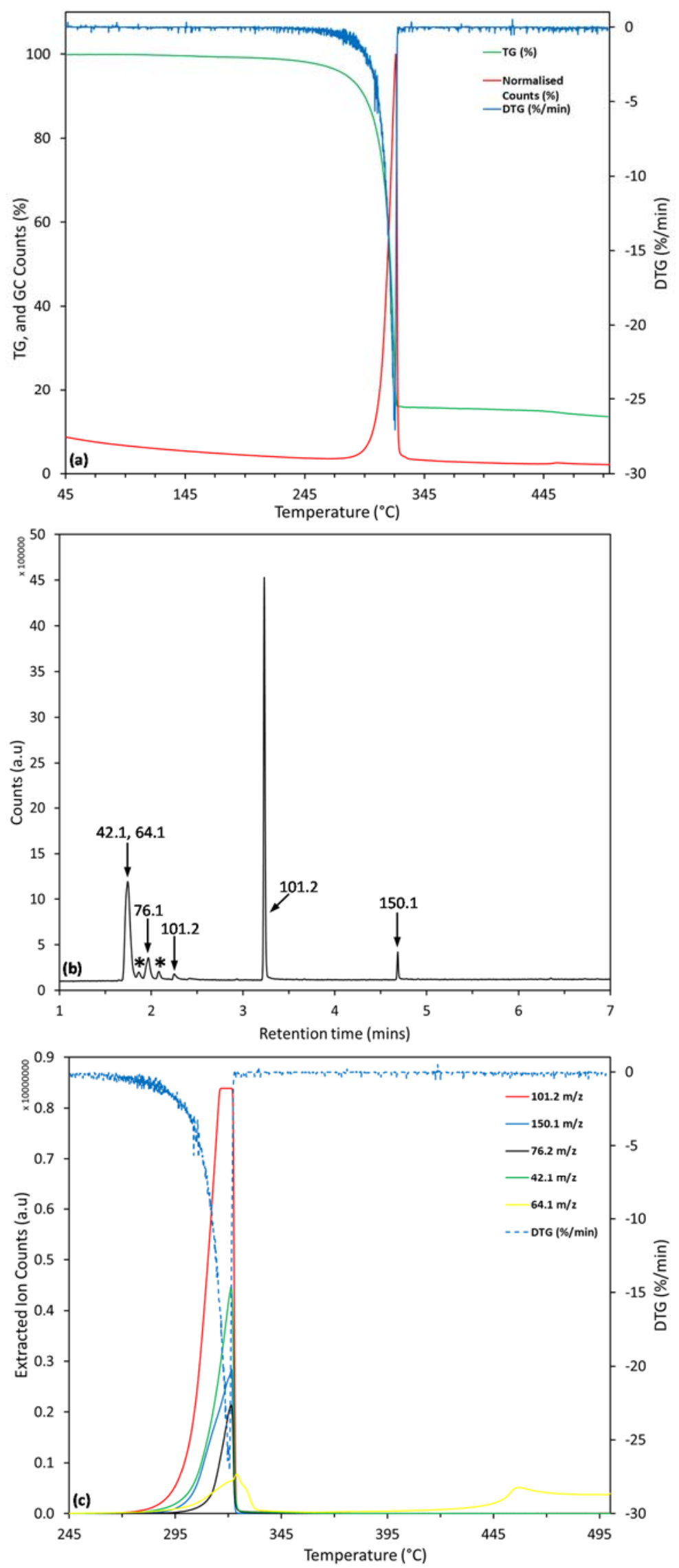

Figure 7: TGA with overlaid MS TIC (a), GC-MS data of furnace atmosphere priorto DTGmax ${ }^{*}=$ partial oxidized species (b) and temporal evolution of main decomposition products (c). 
Thermogravimetric and gas chromatography data are shown in Figure 7. There was no mass loss between $30-200^{\circ} \mathrm{C}$ indicating an absence of water. Mass loss occurred in a single event beginning at $\sim 250{ }^{\circ} \mathrm{C}$, with the maximum rate of mass loss at $320{ }^{\circ} \mathrm{C}$. The mass loss of this event $(84 \%)$ corresponds to the loss of the DIPDTC ligand material, with the exception of one $\mathrm{S}$ per Ni, leading to the formation of NiS (calc. $78 \%$ ). The discrepancy between the calculated and observed mass loss ( $\sim 6 \%)$ of this thermolysis event is attributed to a combination of instrument baseline drift, and partial oxidation of the resultant NiS (evidenced by the formation of $\mathrm{SO}_{2}$ during, and extending slightly beyond, the maximum rate of mass change). A second mass loss event of $\sim 1.5 \%$ was observed between 430 to $500{ }^{\circ} \mathrm{C}$. These results are consistent with previous work ${ }^{[61]}$ although the onset of mass loss occurred $\sim 50{ }^{\circ} \mathrm{C}$ lower than previously reported due to the slower heating rate employed in the current study. Differences in the onset of mass loss between these in situ techniques is attributed to differing thermal environments in sample environment geometries in synchrotron, microscope hotstage and thermogravimetric furnaces.

In-situ gas chromatography mass spectrometry was used to analyse the decomposition products produced during thermolysis (Figure $7 \mathrm{~b}$ ). The volatile species were identified by comparison of their mass fragmentation patterns to a NIST database and are: isopropyl isothiocyanate $(\mathrm{m} / \mathrm{z}=101.2)$, isopropyl amine $(\mathrm{m} / \mathrm{z}=101.2)$, carbon disulfide $(\mathrm{m} / \mathrm{z}=76.2)$, isopropyl disulfide $(\mathrm{m} / \mathrm{z}=150.1)$, sulfur dioxide $(\mathrm{m} / \mathrm{z}=64.1)$ and propene $(\mathrm{m} / \mathrm{z}=42.1)$. Evolved-gas experiments where the furnace atmosphere was continuously monitored by MS provided data describing the temporal evolution of volatile species. Extracted ion chromatographs (Figure 7c) show that volatile species evolve within the same temperature range as the decomposition event and increase in abundance as the rate of mass loss approaches the maximum. Ions arising from isopropyl isothiocyanate and di-isopropyl amine overlap at $\mathrm{m} / \mathrm{z}=101.2$, and thus their evolution during the main mass loss event is convoluted. The co-existence of these species in the gas phase suggests that cleavage of the di-isopropyl N-C bond and the dithiocarbamato $\mathrm{C}=\mathrm{N}$ bond occur nearly simultaneously during decomposition. There were no evolved volatile species following the formation of $\mathrm{NiS}$ until $\sim 430{ }^{\circ} \mathrm{C}$ where sulfur dioxide was 
evolved with a corresponding mass loss of $1.5 \%$ (by TGA). The observation of $\mathrm{SO}_{2}$ during the main mass loss event $\left(245-345^{\circ} \mathrm{C}\right)$, and the secondary mass loss at $\sim 430{ }^{\circ} \mathrm{C}$ indicates that the NiS was oxidized by trace levels of elemental oxygen within the experimental system to $\mathrm{NiO}$, which was also observed in the powder XRD pattern of the final residue in synchrotron experiments (Figure S2).

\section{Conclusions}

Single crystals of $\mathrm{Ni}(\mathrm{DIPDTC})_{2}$ formed NiS upon thermolysis in a single event beginning at $\sim 250$ ${ }^{\circ} \mathrm{C}$. The decomposition of the Ni(DIPDTC) 2 crystals resulted in the formation of $\alpha$-NiS crystals with a structure that retained the approximate shape of the precursor crystals. Analysis of the thermolysis regime using in situ techniques showed that the thermolysis produced no intermediate species and the major volatile by-products were isopropyl-isothiocyanate and carbon disulfide. Thus, our method can be used to synthesize a single phase of nickel sulfide without the need for solvents. The process uses a readily accessible SSP that generates only volatile by-products with no intermediate liquid phase. The resultant nanostructure is highly textured and may provide promising applications in the realms of catalysis and catalytic water splitting.

\section{Experimental Section}

General. Bis( $\kappa^{2} \mathrm{~S}, \mathrm{~S}^{\prime}$-di(isopropyl)dithiocarbamato) nickel(II) (Ni(DIPDTC) 2 ) was synthesized using a published procedure. ${ }^{[61]}$ The complex $(3.0 \mathrm{~g})$ was dissolved in chloroform $(60 \mathrm{~mL})$ and washed several times with ultrapure water. The chloroform layer was dried over anhydrous magnesium sulfate and the volume reduced to $\sim 5 \mathrm{~mL}$ using a rotary evaporator. The concentrated solution was cooled slowly to yield crystals of Ni(DIPDTC)2 suitable for X-ray diffraction experiments.

Optical Microscopy. Variable temperature $\left(30-500{ }^{\circ} \mathrm{C}\right)$ isotropic light microscopy was performed using an Olympus BH-2 microscope fitted with a Linkam THMS600 stage in transmission configuration. Single crystals were placed atop a sapphire wafer and entombed by a silver cover of 3 $\mathrm{mm}$ thickness with $1 \mathrm{~mm}$ aperture. The stage environment was maintained under a flow of nitrogen 
at $25 \mathrm{ml} \mathrm{min}{ }^{-1}$. A heating rate of $3.0{ }^{\circ} \mathrm{C} \mathrm{min}^{-1}$ was used and photomicrographs were taken at $100 \mathrm{x}$ magnification at $3{ }^{\circ} \mathrm{C}$ intervals using a Q-Imaging MicroPublisher 3.3RTV CCD camera.

In Situ X-ray Diffraction. Measurements were performed on the Powder Diffraction beamline at the Australian Synchrotron. The X-ray wavelength was $0.5893 \AA$ (confirmed by refinement against a LaB6 standard). Crystals suitable for single crystal X-ray analysis were ground in an agate pestle and mortar to produce a free flowing green powder, which was loaded into an open-ended $0.3 \mathrm{~mm}$ (internal diameter) quartz capillary. A positive flow of $99.999 \%$ helium through the capillary was used in conjunction with a hot-air blower heating at $3{ }^{\circ} \mathrm{C} \mathrm{min}-1$ to produce 147 diffraction files in the temperature range 25 to $500{ }^{\circ} \mathrm{C}$. Scans were performed in two blocks of 30 second exposure, offset by $0.5^{\circ}$ in the $2 \theta$ range between 2.5 to $60^{\circ}$. The diffraction results were merged and automated peak analysis was performed using software developed in-house. All graphs were generated using MATLAB version 9.2.

Thermogravimetric Analysis. Simultaneous thermogravimetric and calorimetric analysis was performed using a Netzsch STA 449 F5 Jupiter thermal analyser. Samples were placed in a $90 \mu \mathrm{L}$ alumina crucible and experiments were conducted using an atmosphere of $99.9995 \%$ helium, with a residual oxygen concentration of $\sim 50 \mathrm{ppm}$ due to diffusion through instrument orifices. A heating rate of $3{ }^{\circ} \mathrm{C} \mathrm{min}-1$ was employed between 30 to $500{ }^{\circ} \mathrm{C}$. Simultaneous Gas Chromatography-Mass Spectrometry was performed using a heated transfer line from the furnace to an Agilent 7890/5977 Gas Chromatography-Mass Spectrometer. A $\sim 60 \mu \mathrm{L}$ aliquot of furnace atmosphere was automatically sampled in $30{ }^{\circ} \mathrm{C}$ increments and diluted 1:5 with $99.9995 \%$ helium prior to injection through an Agilent HP-5MS column. Separation of volatiles was achieved with a temperature ramp of 50 to 200 ${ }^{\circ} \mathrm{C}$ with a heating rate of $20{ }^{\circ} \mathrm{C} \mathrm{min}-1$. Mass spectra were obtained with a $\mathrm{m} / \mathrm{z}$ range of 50 to $400 \mathrm{amu}$, and referenced to known fragmentation patterns using a NIST 2014 database (NIST 14).

Inductively Coupled Plasma-Mass Spectrometry (ICP-MS). An ICP-MS spectrometer with quadrupole analyser 7500cx (Agilent Technologies, Australia) was used to measure the Ni content in 
the sample after acidic digestion. System optimization and method tuning were performed using a 1 $\%$ nitric acid solution containing $50 \mathrm{ng} \mathrm{mL} \mathrm{mL}^{-1}$ of $\mathrm{Li}, \mathrm{Y}$ and $\mathrm{Tl}$. Operating conditions were RF power $1550 \mathrm{~W}$, RF matching 1.58 V, sample depth $8.0 \mathrm{~mm}$, carrier gas flow $1.0 \mathrm{~L} / \mathrm{min}$, nebulizer pump 0.10 rps, and $\mathrm{S} / \mathrm{C}$ temperature $2.0^{\circ} \mathrm{C}$. Samples were introduced using a micromist concentric nebuliser (Glass Expansion, Agilent Technologies, Australia) and a quartz Scott type double pass spray chamber. Argon was used as a plasma gas. Calibration was carried out using single element solutions containing ${ }^{60} \mathrm{Ni}$ (High-Purity Standards). Calibration solutions were prepared at concentrations ranging from 1 to $1000 \mathrm{ng} \mathrm{mL}^{-1}$. A $100 \mathrm{ng} \mathrm{mL}^{-1}$ solution of ${ }^{103} \mathrm{Rh}$ (High-Purity Standards) was used as internal standard. The calibration curve showed linearity over the range of concentrations with a correlation factor $\left(\mathrm{r}^{2}\right)$ of $0.99 . \alpha$-NiS $\left(1.17 \mathrm{mg}\right.$ ) was digested using $3 \mathrm{~mL}$ of $69 \% \mathrm{HNO}_{3}$ (Ultra High Purity, Seastar) at $35{ }^{\circ} \mathrm{C}$. The sample was then diluted with ultra-pure water $(1: 1000)$ and analysed by ICP-MS within 24 hours. Analytical precision (for three injections) had RSD $<5 \%$ and accuracy was in the range $98-100 \%$.

Electron Microscopy. Thermolysis products were imaged using a Zeiss Supra 55VP scanning electron microscope (operating in High-Vacuum mode) with an Oxford Instruments INCA X-Sight 7558 for energy dispersive X-ray spectroscopy. Transmission electron microscope imaging was performed using a FEI Tecnai T20 TWIN microscope $\left(\mathrm{LaB}_{6}\right)$ and an accelerating voltage of $200 \mathrm{kV}$.

\section{Acknowledgments}

We acknowledge Dr Ronald Shimmon for laboratory assistance. We are in gratitude to the Mark Wainwright Analytical Centre, UNSW, for access to a single crystal X-ray diffractometer. We thank technical staff at the Australian Synchrotron for their assistance. This research is supported by an Australian Government Research Training Program Scholarship.

\section{References}

[1] L.-L. Feng, G. Yu, Y. Wu, G.-D. Li, H. Li, Y. Sun, T. Asefa, W. Chen, X. Zou, J. Am. Chem. Soc., 137 (2015) 14023-14026. 
[2] P. Luo, H. Zhang, L. Liu, Y. Zhang, J. Deng, C. Xu, N. Hu, Y. Wang, ACS Appl. Mater. Interfaces, 9 (2017) 2500-2508.

[3] W. Zhang, Y. Wang, Z. Wang, Z. Zhong, R. Xu, Chem. Commun., 46 (2010) 7631-7633.

[4] L. Zhang, B. Tian, F. Chen, J. Zhang, Int. J. Hydrogen Energy, 37 (2012) 17060-17067.

[5] Y. Pan, Y. Chen, X. Li, Y. Liu, C. Liu, RSC Adv., 5 (2015) 104740-104749.

[6] X.L. Wu, B. Yang, Z.J. Li, L.C. Lei, X.W. Zhang, RSC Adv., 5 (2015) 32976.

[7] C. Kong, S. Min, G. Lu, ACS Catal., 4 (2014) 2763-2769.

[8] T. Zhu, H.B. Wu, Y. Wang, R. Xu, X.W.D. Lou, Adv. Energy Mater., 2 (2012) 1497-1502.

[9] A. Olivas, J. Cruz-Reyes, V. Petranovskii, M. Avalos, S. Fuentesa, J. Vac. Sci. Technol. A, 16 (1998) 3515-3520.

[10] J. Yang, X. Duan, Q. Qin, W. Zheng, J. Mater. Chem. A, 1 (2013) 7880-7884.

[11] H. Pang, C. Wei, X. Li, G. Li, Y. Ma, S. Li, J. Chen, J. Zhang, Sci. Rep., 4 (2014) 3577.

[12] Y. Zhang, W. Sun, X. Rui, B. Li, H.T. Tan, G. Guo, S. Madhavi, Y. Zong, Q. Yan, Small, 11 (2015) 3694-3702.

[13] W. Zhou, X. Cao, Z. Zeng, W. Shi, Y. Zhu, Q. Yan, H. Liu, J. Wang, H. Zhang, Energy Environ. Sci., 6 (2013) 2216-2221.

[14] S.B. Ni, X.L. Yang, T. Li, J. Mater. Chem., 22 (2012) 2395-2397.

[15] S. Ji, L. Zhang, L. Yu, X. Xu, J. Liu, RSC Adv., 6 (2016) 101752-101759.

[16] S.-C. Han, K.-W. Kim, H.-J. Ahn, J.-H. Ahn, J.-Y. Lee, J. Alloys Compd., 361 (2003) 247-251.

[17] N.H. Idris, M.M. Rahman, S.-L. Chou, J.-Z. Wang, D. Wexler, H.-K. Liu, Electrochim. Acta, 58 (2011) 456-462.

[18] Z. Liu, X. Zheng, S.-L. Luo, S.-Q. Xu, N.-Y. Yuan, J.-N. Ding, J. Mater. Chem. A, 4 (2016) 13395-13399.

[19] N. Mahmood, C. Zhang, Y. Hou, Small, 9 (2013) 1321-1328.

[20] K. Aso, A. Hayashi, M. Tatsumisago, Electrochim. Acta, 83 (2012) 448-453.

[21] X. Sun, J. Dou, F.Y. Xie, Y.F. Li, M.D. Wei, Chem. Commun., 50 (2014) 9869-9871. 
[22] J. Yang, C. Bao, K. Zhu, T. Yu, F. Li, J. Liu, Z. Li, Z. Zou, Chem. Commun., 50 (2014) 48244826.

[23] H.K. Mulmudi, S.K. Batabyal, M. Rao, R.R. Prabhakar, N. Mathews, Y.M. Lam, S.G. Mhaisalkar, PCCP, 13 (2011) 19307-19309.

[24] X. Wang, B. Batter, Y. Xie, K. Pan, Y. Liao, C. Lv, M. Li, S. Sui, H. Fu, J. Mater. Chem. A, 3 (2015) 15905-15912.

[25] S. Peng, L. Li, H. Tan, R. Cai, W. Shi, C. Li, S.G. Mhaisalkar, M. Srinivasan, S. Ramakrishna, Q. Yan, Adv. Funct. Mater., 24 (2014) 2155-2162.

[26] Y. Liao, K. Pan, Q. Pan, G. Wang, W. Zhou, H. Fu, Nanoscale, 7 (2015) 1623-1626.

[27] H. Sun, D. Qin, S. Huang, X. Guo, D. Li, Y. Luo, Q. Meng, Energy Environ. Sci., 4 (2011) 26302637.

[28] Y. Zhou, D. Yan, H. Xu, J. Feng, X. Jiang, J. Yue, J. Yang, Y. Qian, Nano Energy, 12 (2015) 528-537.

[29] Q. Liu, A. Diaz, A. Prosvirin, Z. Luo, J.D. Batteas, Nanoscale, 6 (2014) 8935-8942.

[30] L. Shen, J. Wang, G. Xu, H. Li, H. Dou, X. Zhang, Adv. Energy Mater., 5 (2015) 1400977.

[31] J. Xiao, L. Wan, S. Yang, F. Xiao, S. Wang, Nano Lett., 14 (2014) 831-838.

[32] X.Y. Yu, L. Yu, L. Shen, X. Song, H. Chen, X.W.D. Lou, Adv. Funct. Mater., 24 (2014) 74407446.

[33] H. Li, Y. Shao, Y. Su, Y. Gao, X. Wang, Chem. Mater., 28 (2016) 1155-1164.

[34] C. Gervas, S. Mlowe, M.P. Akerman, I. Ezekiel, T. Moyo, N. Revaprasadu, Polyhedron, 122 (2017) 16-24.

[35] C. Buchmaier, M. Glänzer, A. Torvisco, P. Poelt, K. Wewerka, B. Kunert, K. Gatterer, G. Trimmel, T. Rath, J. Mater. Sci., 52 (2017) 10898-10914.

[36] G. Kullerud, R.A. Yund, Journal of Petrology, 3 (1962) 126-175.

[37] J.C. Barry, S. Ford, J. Mater. Sci., 36 (2001) 3721-3730. 
[38] K. Ramasamy, M.A. Malik, P. O’Brien, J. Raftery, M. Helliwell, Chem. Mater., 22 (2010) 63286340.

[39] M.V. Swain, J. Mater. Sci., 16 (1981) 151-158.

[40] A. Ghezelbash, B.A. Korgel, Langmuir, 21 (2005) 9451-9456.

[41] M. Liu, G. Lv, G. Chen, Y. Qin, P. Sun, K. Zhou, X. Xing, C. He, RSC Adv., 6 (2016) 102472102481.

[42] P. Gaikar, S.P. Pawar, R.S. Mane, M. Nuashad, D. Shinde, RSC Adv., 6 (2016) 112589-112593.

[43] A. Molla, M. Sahu, S. Hussain, Sci. Rep., 6 (2016) 26034.

[44] C. Wei, C. Cheng, J. Zhao, Y. Wang, Y. Cheng, Y. Xu, W. Du, H. Pang, Chem-Asian J., 10 (2015) 679-686.

[45] S. He, C. Lu, G.-S. Wang, J.-W. Wang, H.-Y. Guo, L. Guo, ChemPlusChem, 79 (2014) 569576.

[46] X. Jiang, Y. Xie, J. Lu, L. Zhu, W. He, Y. Qian, Adv. Mater., 13 (2001) 1278-1281.

[47] J. Wang, D. Cao, G. Yang, Y. Yang, H. Wang, J. Solid State Electrochem., 21 (2017) 30473055.

[48] N. Alam, M.S. Hill, G. Kociok-Köhn, M. Zeller, M. Mazhar, K.C. Molloy, Chem. Mater., 20 (2008) 6157-6162.

[49] P.R. Bonneau, R.K. Shibao, R.B. Kaner, Inorg. Chem., 29 (1990) 2511-2514.

[50] D. Mondal, G. Villemure, G. Li, C. Song, J. Zhang, R. Hui, J. Chen, C. Fairbridge, Appl. Catal., A, 450 (2013) 230-236.

[51] R. Boughalmi, R. Rahmani, A. Boukhachem, B. Amrani, K. Driss-Khodja, M. Amlouk, Mater. Chem. Phys., 163 (2015) 99-106.

[52] Y. Fazli, S. Pourmortazavi, I. Kohsari, M. Karimi, M. Tajdari, J. Mater. Sci. - Mater. Electron., 27 (2016) 7192-7199.

[53] P. O'Brien, J.H. Park, J. Waters, Thin Solid Films, 431-432 (2003) 502-505. 
[54] A. Roffey, N. Hollingsworth, H.U. Islam, M. Mercy, G. Sankar, C.R. Catlow, G. Hogarth, N.H. de Leeuw, Nanoscale, 8 (2016) 11067-11075.

[55] C. Xiangying, W. Zhenghua, W. Xiong, W. Junxi, L. Jianwei, Q. Yitai, Chem. Lett., 33 (2004) 1294-1295.

[56] N. Hollingsworth, A. Roffey, H.-U. Islam, M. Mercy, A. Roldan, W. Bras, M. Wolthers, C.R.A. Catlow, G. Sankar, G. Hogarth, N.H. de Leeuw, Chem. Mater., 26 (2014) 6281-6292.

[57] B. Arul Prakasam, M. Lahtinen, A. Peuronen, M. Muruganandham, E. Kolehmainen, E. Haapaniemi, M. Sillanpää, Inorg. Chim. Acta, 425 (2015) 239-246.

[58] E. Sathiyaraj, G. Gurumoorthy, S. Thirumaran, New J. Chem., 39 (2015) 5336-5349.

[59] J.I.K. Yun Ku Jung, Jin-Kyu Lee, J. Am. Chem. Soc., 132 (2010) 178-184.

[60] B.F. Ali, W.S. Al-Akramawi, K.H. Al-Obaidi, A.H. Al-Karboli, Thermochim. Acta, 419 (2004) $39-43$.

[61] A. Angeloski, A.T. Baker, M. Bhadbhade, A.M. McDonagh, J. Mol. Struct., 1113 (2016) 127132.

[62] J. Cheon, D.S. Talaga, J.I. Zink, Chem. Mater., 9 (1997) 1208-1212.

[63] N. Pradhan, B. Katz, S. Efrima, J. Phys. Chem. B, 107 (2003) 13843-13854.

[64] L. Barry, J.D. Holmes, D.J. Otway, M.P. Copley, O. Kazakova, M.A. Morris, J. Phys.: Condens. Matter, 22 (2010) 076001.

[65] L.K. Macreadie, H.E. Maynard-Casely, S.R. Batten, D.R. Turner, A.S.R. Chesman, ChemPlusChem, 80 (2015) 107-118.

[66] M.D. Khan, G. Murtaza, N. Revaprasadu, P. O'Brien, Dalton Trans, 47 (2018) 8870-8873.

[67] P.P. Nash, A. International, Phase diagrams of binary nickel alloys, ASM International1991.

[68] D.W. Bishop, P.S. Thomas, A.S. Ray, P. Simon, J. Therm. Anal. Cal., 64 (2001) 201-210.

[69] C.I. Pearce, R.A.D. Pattrick, D.J. Vaughan, Rev. Mineralogy Geochemistry, 61 (2006) 127-180.

[70] R.C. Sharma, Y.A. Chang, Metall. Trans. , 11B (1980) 139-146. 